\title{
Improving family planning services in public health facilities to reach more women
}

Caroline W. Kabiru

Jessica Brinton

Joyce Mumah

Carol Mukiira

Chimaraoke O. Izugbara

Follow this and additional works at: https://knowledgecommons.popcouncil.org/departments_sbsr-rh

Part of the Demography, Population, and Ecology Commons, Family, Life Course, and Society Commons, Gender and Sexuality Commons, International Public Health Commons, Maternal and Child Health Commons, Public Health Education and Promotion Commons, and the Women's Health Commons How does access to this work benefit you? Let us know!

\section{Recommended Citation}

Kabiru, Caroline W., Jessica Brinton, Joyce Mumah, Carol Mukiira, and Chimaraoke O. Izugbara. 2014. "Improving family planning services in public health facilities to reach more women," STEP UP Policy Brief. Nairobi: APHRC. 
POLICY BRIEF
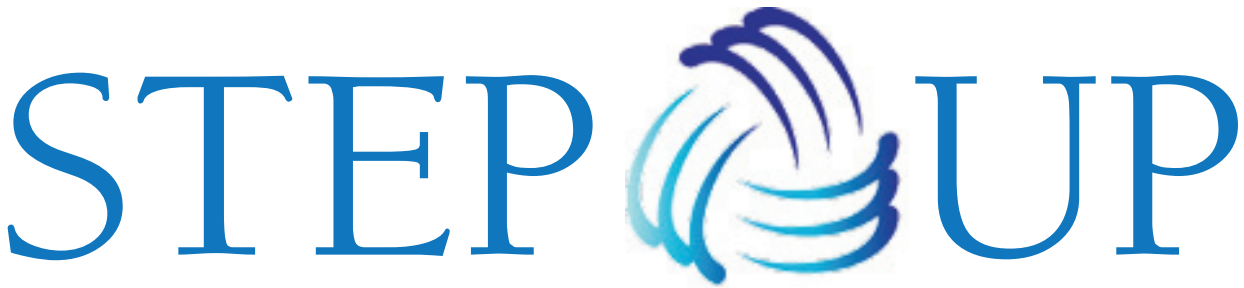

STRENGTHENING EVIDENCE FOR PRORAMMING ON UNINTENDED PREGNANCY

MAY 2014

STEP UP generates policy-relevant research to promote an evidencebased approach for improving access to family planning and safe abortion.

We work in Bangladesh, northern India, Ghana, Kenya, and Senegal.

Population Council Coordinating Partner

African Population and Health Research Center

icddr,b

London School of Hygiene and Tropical Medicine

Marie Stopes International

Partners in Population and Development

Funded by

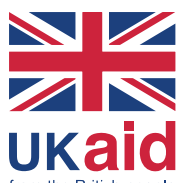

from the British people

IMPROVING FAMILY PLANNING SERVICES IN PUBLIC HEALTH FACILITIES TO REACH MORE WOMEN

\section{FAMILY PLANNING SERVICES: CRITICAL BUT INADEQUATE}

Nearly half of the pregnancies that occur annually in Kenya are unintended - not wanted or wanted at a later time. Yet modern contraceptive use remains low, at $39 \%$. The high number of unintended pregnancies results largely from an unmet need for contraceptives.

Unintended pregnancies have significant implications for the health and wellbeing of women and children:

- Women with unintended pregnancies are less likely to seek and receive adequate antenatal care.

- They are also more likely to terminate their pregnancies, often through unsafe methods.

Unintended pregnancies therefore contribute significantly to maternal and child death, illness, and disability.

Although Kenya has made significant progress in ensuring its citizens' right to reproductive health, many Kenyans still lack access to or fail to use contraceptives, in part because of the lack of quality family planning (FP) services.

The public sector is a critical source of FP services - nearly half of all women (and the majority of rural and urban poor women) obtain contraception from public sources. The centrality of public health facilities in providing FP services means that the Ministry of Health (through DRH) has a major role to play in ensuring access to FP services. Yet public facilities face fundamental challenges.

Through the STEP UP research programme, APHRC developed a comprehensive Country Profile Report that outlines the status, causes, and consequences of unintended pregnancy in Kenya. The study involved a thorough and systematic desk review, secondary analyses of available datasets, and in-depth interviews with a wide range of key stakeholders. One of the most prominent findings was how important public health facilities are to reducing unmet need for FP .

\section{RECOMMENDATIONS}

The MOH (through DRH) and county departments of health must ensure that:

- Public health facilities provide a wide range of FP options, in order to meet varying client needs.

- Public facilities have the requisite infrastructure to support adequate FP service provision, including private space for counselling and exams, visual aids for clients, and written guidelines.

- Public facilities have health workers sufficiently trained to provide quality FP services. It is essential that in-service training is routinely performed to ensure that clients receive the most accurate FP information.

- There is a well-coordinated effort to implement comprehensive FP programmes in public facilities that lack them.

An effective audit and logistics system is established that tracks resources, reduces supply stock-outs, and monitors the hiring, supervision, and continuous training of quality staff. 


\section{PUBLIC FACILITIES AND FP SERVICES: WHAT ARE THE CHALLENGES?}

Although virtually all public facilities offer FP services, the range of available options is limited.

- While $96 \%$ offered at least one modern method of contraception in 2010 , only $11 \%$ provided male or female sterilization.

- Only $10 \%$ of public facilities could provide pelvic examination, which is essential for provision of the intrauterine device (IUD) method.

The limited range of contraceptives means that some clients cannot find a suitable method. Consequently, method-related dissatisfaction is one of the most common reasons why women discontinue contraception, and without suitable alternatives, many women may opt not to use contraception at all.

Family planning service provision is most successful when there is adequate infrastructure for quality services. However, as shown in Figure 1, few facilities have adequate basic capacities. Critical missing infrastructure includes:

- Space that provides sufficient privacy for counselling and physical examination;

- Visual aids for client education;

- Provider guidelines and protocols for FP services;

- Equipment and supplies needed to provide each FP method offered;

- Capacity to provide treatment for sexually transmitted infections, HIV counselling and testing services, infection control, and anti-retroviral therapy services to those who need them.

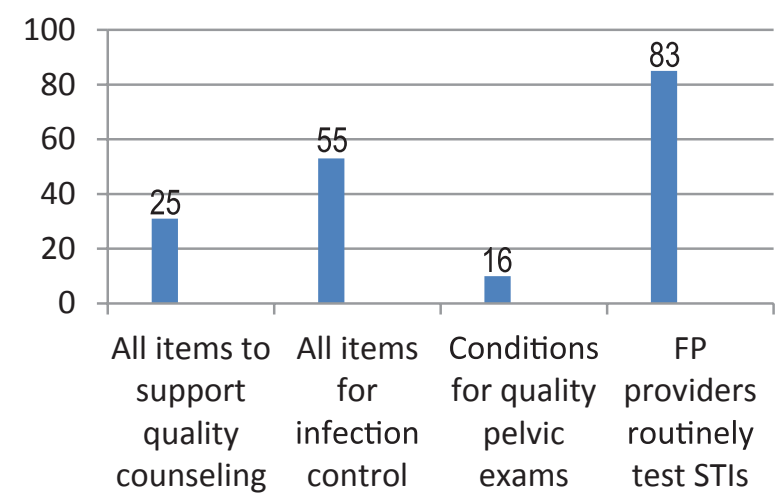

Figure 1: Percentage of public facilities offering temporary FP methods and the relative presence of critical infrastructure

\section{USEFUL DEFINITION}

\section{What is unmet need for family planning?}

\section{A woman has an unmet need if she is}

\section{sexually active, does not want another}

\section{child or wants to delay pregnancy, but she}

$$
\text { is not using any FP method. }
$$

Meeting Kenya's goal of ensuring that all citizens have a right to quality reproductive health care requires that each public facility have trained personnel who are able to provide first-rate maternal health services.

In order to achieve this, regular training and supervision are critical to ensuring that providers develop technical skills and are exposed to new knowledge. However, although routine general supervision occurs in all facilities, the 2010 Kenya Service Provision Assessment survey shows that only $21 \%$ of providers in government facilities reported any FP-related training in the year preceding the survey.

\section{THE WAY FORWARD}

Kenya has made progress in recent years in expanding access to maternal health and FP services, but maternal mortality remains unacceptably high (488 per 100,000 women in 2010). In order to solidify gains achieved, and make further progress, concerted commitment from the Kenya Government and Ministry of Health to actively support family planning services in public facilities is crucial.

\section{SUGGESTED READINGS:}

1. Marston C, Cleland J. Do unintended pregnancies carried to term lead to adverse outcomes for mother and child? An assessment of five developing countries. Population Studies. 2003;57(1):77-93.

2. Ali MM, Cleland J, Shah $\mathrm{IH}$. Causes and consequences of contraceptive discontinuation: evidence from 60 Demographic and Health Surveys. Geneva: World Health Organization; 2012

3 Mumah, J, Kabiru, CW, Mukiira, C, Brinton, J, Mutua, M, Izugbara, C, Birungi, H. and Askew, I. Unintended Pregnancies in Kenya: A Country Profile. Nairobi: African Population and Health Research Center; 2014.

\section{Suggested citation:}

Kabiru, CW, Brinton, J, Mumah, J, Mukiira C, Izugbara, C. 2014. "Improving Family Planning Services in Public Health Facilities to Reach More Women," STEP UP Policy Brief, May 2014. Nairobi: APHRC. 